\title{
Communicative skills in Spanish children with Autism Spectrum Disorder and children with Attention Deficit Hyperactivity Disorder. Analysis through parents' perceptions and narrative production
}

\section{Introduction}

Recent studies have highlighted the diagnostic conundrum that clinicians often face when establishing differential diagnoses of verbally fluent school-age children with Autism Spectrum Disorder (ASD) and Attention Deficit Hyperactivity Disorder (ADHD) (Grzadzinski, Dick, Lord, \& Bishop, 2016). These two neurodevepmental disorders show a high co-occurrence; in fact, there is an overlap in genetic, neurobiological and neuropsychological bases, such as executive functioning or theory of mind skills (Miranda, Baixauli, Colomer y Roselló, 2013). One relevant aspect that can shed light on this complex topic is the analysis of communication. Persistent deficits in social communication are present across the autism spectrum (Schuh, Eigsti, \& Mirman, 2016) and, even if they are not included in the core diagnostic criteria, language and pragmatic disturbances may often occur in ADHD (Bellani, Moretti, Perlini, \& Brambilla, 2011; Green, Johnson, \& Bretherton, 2014).

Studies that have compared the communicative competence in ADHD and in ASD (specifically, high functioning autism, without language impairment) have mainly used the Children's Communication Checklist (CCC-2) (Bishop, 2003), designed to assess social-communicative impairments in daily interactions. Research has found similar deficits in both populations on coherence and inappropriate initiations. However, they do not seem to be as severe in ADHD as in ASD, where the impairment is more pronounced in the interpretation of the context, nonverbal communication, and stereotyped language (Geurts et al., 2004; Geurts \& Embrecths, 2008; Helland, Biringer, Helland, \& Heimann, 2012; Kuijper, Hartman, Bogaerds-Hazenberg, \& Hendriks, 2017).

One of the main dimensions of communicative competence is narrative ability, which has proven to be a vulnerable domain in both ASD and ADHD. A meta-analysis about this topic in children with ASD found significant deficits in macrostructure (coherence and cohesive adequacy), microstructure (productivity and grammar) and internal state language (Baixauli, Colomer, 
Roselló, \& Miranda, 2016). Children with ADHD experience difficulties in the elaboration and comprehension of stories as well, which is probably related to the cognitive characteristics of the disorder (Green et al., 2014; Ygual, Roselló, \& Miranda, 2010). Despite these evidences, to the best of our knowledge, only two studies have tried to perform a comparative analysis of the narrative discourse produced by individuals with ADHD and with ASD, both using Tuesday (Wiesner, 1998), a story included in the Autism Diagnostic Observation Schedule (ADOS) (Lord, Rutter, DiLavore, \& Risi, 2000). First, Rumpf, Kamp-Becker, Becker and Kauschke (2012) found a similar performance in children with ASD, ADHD and typical development (TD) on aspects such as variety of syntactic structures, mean utterance length and use of connectors. However, the groups with ASD and ADHD produced significantly shorter and less coherent narrations than the TD group. Moreover, the group with ASD produced significantly fewer pronominal references and cognitive internal state terms compared to the group with ADHD and TD. More recently, Kuijper et al. (2017) found similarities between the groups with ADHD, ASD and TD, regarding story length. Similar to Rumpf et al.'s (2012) findings, children with ADHD and ASD showed difficulties in producing a coherent narrative. However, participants with ASD had more limitations regarding syntactic complexity and children with ADHD had more problems in their choice of referring expressions and speech fluency. The study by Kuijper et al. (2017) went one step further by analyzing the associations between the CCC-2 and narrative skills, obtaining a moderate correlation. In addition, significant correlations were also found between narrative ability, theory of mind and working memory in both clinical groups.

From our point of view, the CCC-2 and the narrative task offer complementary but different information. The analysis of the narrative ability provides very relevant data, such as quantitative indicators about language samples. Although narratives involve a degree of pragmatic skill, they are more formal than everyday conversations and they have been shown predictive capacity of academic achievement (Griffin, Hemphill, Camp, \& Wolf, 2004). This information would be difficult to obtain from questionnaires that assess everyday communication and can also present limitations, such as the subjectivity of the informants, who have to correctly interpret the skills evaluated. By contrast, parent or teacher reports give a more representative account of the child's behavior in everyday situations. 
In conclusion, the identification of possible specific communication impairments across ADHD and ASD may help in the consideration of more appropriate intervention objectives. In this sense, it is crucial to explore the utility of narrative measures which are administered by trained clinicians versus questionnaire measures based on parent or teacher ratings. Consequently, the present study proposes the following objectives:

- To analyze the similarities and differences in the linguistic and communicative skills of children with ADHD, ASD, and TD, assessed using two different methods: parent ratings on the CCC-2 and a narrative task.

- To identify the relative importance of the CCC-2 subscales and the narrative task indicators in discriminating between children with ASD versus children with ADHD, as well as the classification power of each assessment method.

Our study extends previous research by introducing the examination of variables related to discourse expression and comprehension, in addition to the type of analysis employed to determine the discriminant capacity of the procedures used to assess the communicative skills. Furthermore, the cultural and linguistic context in which the study is developed is different from that of previous investigations, which have been carried out in other countries. This consideration is even more noteworthy if we take into account that pragmatic language abilities are highly susceptible to cultural variation. Aspects such as turn taking, use of humor, eye contact and other nonverbal strategies for maintaining interaction are largely determined by cultural rules. Given that different languages and cultures might organize social interactions differently, cross-linguistic studies are crucially relevant. Summarizing, when assessing language and communication, it is important to consider the impact of language specific features on the manifestation of neurodevelopmental disorders (Leonard, 2009).

\section{Methods}

\subsection{Participants}

Participants in this study were 124 children between 7 and 11 years old. They had an intelligence quotient (IQ) equal to or above 80, measured by the K-BIT (Kaufman \& Kaufman 2000), and were distributed in three groups: 37 children with TD, 52 children with ASD (severity level 1, according 
to the Diagnostic and Statistical Manual of Mental Disorders- Fifth Edition, DSM-5, APA, 2013), and 35 children with $A D H D$, matched on age and IQ. Of them, $83.1 \%$ of the participants were boys, and $16.9 \%$ were girls. The general language level was evaluated by the vocabulary subtest of the Wechsler Intelligence Scale for Children - Fourth Edition (WISC-IV) (Wechsler, 2003), which revealed significant differences between the groups analyzed (see table 1). The vocabulary score of the ADHD group was significantly lower than the group with TD $(p<.001)$, while there were no significant differences between the TD and the ASD groups $(p=.081)$.

The participants with ASD and ADHD were selected from 36 schools and they had received a clinical diagnosis in the Neuropsychiatry services in medical centers in Valencia. In order to confirm the diagnosis of ASD, the strict cut-off points recommended in the Social Communication Questionnaire (SCQ; Rutter, Le Couteur, \& Lord, 2003) and in the Revised Autism Diagnostic Interview (ADI-R; Rutter, \& Lord, 2006) were applied. To corroborate the diagnosis, the parents and teachers of the children with ADHD filled out the 18 criteria for ADHD from the DSM-5 (APA, 2013). Considering the ratings of the parents and teachers, $77.1 \%$ of the participants showed a combined presentation, that is, they exhibited six or more inattentive symptoms and six or more hyperactivity/impulsivity symptoms. On the other hand, $22.9 \%$ showed a presentation with predominance of inattention (six or more inattentive symptoms). The children with TD were selected in the same schools where the clinical sample was obtained. None of them presented a history of psychopathologies or criteria for ASD or ADHD diagnosis according to DSM-5.

The exclusion criteria for all groups were having an IQ of less than 80 , and severe genetic or neurological diseases, brain lesions, psychosis, visual, auditory, and motor or sensorial deficits. The sociocultural level of the parents of the groups with ASD and with TD, measured by the educational level reached, was higher than the sociocultural level of the parents of the group with ADHD, and so it was included as covariate in the analyses.

The study was approved by the Ethics Committee of the University of CITY (Helsinki Declaration, 1964). Likewise, it had the authorization of the Board of Education of the Government to access the school and locate the participants. The tests were applied by experienced professionals who were familiar with the use of the different instruments. The 
parents were personally informed about the purpose of the study, and they provided their written informed consent, in addition to the oral consent of all the children who participated. -Insert table 1-

\subsection{Instruments}

\subsubsection{Assessment of the communicative competence in everyday settings: The Children's Communication Checklist Second Edition (CCC-2)}

The CCC-2 (Bishop, 2003) is a questionnaire designed to identify the pragmatic language disorder in children with communication problems. It presents good internal consistency and validity index (Norbury, Nash, Baird, \& Bishop, 2004) and includes 70 items grouped in 10 subscales that measure different aspects of communication: four scales assess the structure of the language (speech, syntax, semantics, coherence), four scales assess pragmatics (inappropriate initiation, stereotyped language, the use of context, and non-verbal communication), and two scales assess the behaviors that are affected in children with ASD (social relationships and interests). In this study it was filled out by the parents.

The frequency of the behaviors described in each item is rated on a 4-point scale. The direct scores are converted into scalar scores with a mean of 10 and a standard deviation of 3 , with higher scores indicating better performance. A global measure of communication, the general communication composite (GCC), is obtained by adding up the scalar scores of the first eight subscales. The GCC distinguishes between children with communication problems and children with TD. In addition, and following previous studies like the one by Helland, Helland and Heimann (2014), a non-standardized pragmatic composite (PC) is included, based on the results from the coherence, inappropriate initiation, stereotyped language, use of context, and non-verbal communication scales. A low score on these general indices indicates greater impairment.

Internal consistency reliability coefficients for the CCC-2 range from .77 to .85 for all subscales across age groups (Bishop 2003). The Spanish version of the questionnaire is highly valid and reliable, classifying correctly $98.9 \%$ of grouped cases with and without pragmatic disorder 
(Crespo-Eguílaz, Magallón, Sánchez-Carpintero \& Narbona, 2016). The scales also have good reliability in the sample of the present study (Cronbach's alpha: 0.932 ).

\subsubsection{Assessment of narrative competence}

The narrations were elicited using the picture book Frog Goes to Dinner (Mayer, 1974), that contains 16 pages with illustrations and no text. It deals about a boy who takes his frog to a restaurant. Once there, the frog jumps out of the boy's pocket and becomes involved in various episodes before the boy finds him. This book includes some examples of deceptions and tricks, providing a rich context to describe the emotional and cognitive states of the main characters (Siller, Swanson, Serlin, \& George, 2014).

The participants were presented with the book so they could look at the pictures and familiarize themselves with the story. When the child finished looking at the story, s/he was asked to tell the story, with the possibility of having the book in front of him/her. Narratives were audiorecorded. The prompting offered by the examiner was minimal (e.g. "What happened next?", "Tell me more"). Once the narration had ended, seven inferential questions were asked, adapted from Strong (1998).

A member of the research group transcribed and codified all the narrations, using the program Systematic Analysis of Language Transcripts (SALT, Miller, \& Chapman, 2000). The narrations were segmented in communication units (C-Units), defined as a main clause and all the subordinate clauses linked to it (Loban, 1976).

To assess the narrative ability, these indicators were codified:

- Indicators of verbal productivity. The number of utterances or C-Units was considered.

- Syntactic indicators:

- Mean length of utterance (MLU), calculated by dividing the number of words by the number of C-Units.

- Syntactic complexity. The total number of complex communication units, that is, those containing an independent clause and at least one dependent clause in the narration 
- Grammatical errors, related to agreement, word order, and omissions, substitutions, or additions of functional words.

- Semantic indicators. They were selected because of their utility in cross-disorder studies about narrative language (Norbury, Gemmel, \& Paul, 2014):

- Semantic errors. These are substitutions of terms, related semantically, but used incorrectly ("glass" instead of "cup").

- Pedantic language. These are excessively formal expressions or ones that the child uses in an inappropriate way for the context ("manifest" instead of "show, point to").

- Pragmatic indicators:

- Cohesive adequacy errors. They refer to the number of markers that did not "tie" clearly to a single preceding noun phrase antecedent (Banney, Harper-Hill, \& Arnott, 2015; Liles, 1985). For example, "a frog fell on his face", where it is not possible to infer on whose face the frog fell.

- Irrelevant details. These are defined as insignificant and excessively detailed comments that affect the overall coherence of the story (Barnes \& Baron-Cohen, 2012). For example: "The child is sitting and then the child is standing up".

- Misattributions. They refer to erroneous interpretations that result in semantic breaks violating the veracity of the story. Consequently, incorrect information is conveyed. It is an indicator of narrative production, which is the result of failures in the understanding of the visual story. For example, "the child looks in the mirror because it bothers him".

- Perseverations. They consist of word repetitions or the recurrence of the same idea (Norbury et al., 2014). For example: "the frog gets into the coat, the frog gets into the pocket"; "the waiter gets angry, he gets in the salad and the waiter gets angry".

Finally, in order to assess the inferential comprehension of the story, seven questions were asked, adapted from Strong (1998). They evaluated information not explicitly expressed in the pictures, but that could be determined by the correct attribution of motivations or mental states that lead to the characters' behavior or through an adequate interpretation of the context (e.g., 
why did the frog hide in the child's pocket; why did the child's dad tell him to go right to bed; why was the child's family angry?...).

All narrative coding was completed by $\mathrm{PhD}$ research assistants, blind to the participants' diagnostic status. The principal investigator coded all the transcriptions. A second judge, trained in narrative coding, coded $25 \%$ of the narratives, randomly chosen, to establish interrater reliability. This was calculated by dividing the number of agreements into the number of agreements plus disagreements, and multiplying the result by 100 to obtain a percentage score. In the case of the segmentation into C-Units, agreement reached $95 \%$; for the quantification of the complex C-Units, $90 \%$; for grammatical errors, $92 \%$; for semantic errors, $85 \%$; for pedantic language, $90 \%$; for cohesive adequacy errors, $87 \%$; for irrelevant details, $82 \%$; for misattributions, 84\%; and for perseverations, $85 \%$. All disagreements were resolved by discussion.

\section{Results}

\subsection{Statistical analyses}

The statistical analyses were performed with the Statistical Package for the Social Science (SPSS) version 22.00 software. Preliminary analyses were conducted to examine the distribution of the variables using the Kolmogorov-Smirnov test; those variables that did not show a normal distribution were transformed using square-root transformation.

To analyze the differences between the groups with TD, ASD, and ADHD on the variables selected from the CCC-2 and the variables from the narrative task, two multivariate analyses of covariance (MANCOVA) were conducted, using gender, vocabulary, and parents' educational level as covariates. The differences on the tests were verified through covariate analyses of variance (ANCOVAs). For the additional ANCOVAs, the level of significance was set at $p<.004$ in the comparison of the different domains of the CCC-2, after applying the Bonferroni correction, and the value of $\eta^{2 p}$ was calculated to test the strength of the association. Similarly, in the comparison of the variables from the narrative task, a significance level of $p<.005$ was established, after applying the Bonferroni correction, dividing alpha by the 11 variables introduced in the analysis. 
To identify the best combination of CCC-2 subscales, on the one hand, and of the narrative task skills, on the other, two linear discriminant function analyses were run with the step-wise method using the crossed-validation procedure. Although for some variables there were deviations from the normal distribution, discriminant analysis is considered sufficiently robust to handle skewed data (Kinnear \& Gray, 2000). In the first discriminant analysis, the independent variables introduced were the scalar scores from all the CCC-2 subscales that measure communicative competences (speech, syntax, semantics, coherence, inappropriate initiations, stereotyped language, use of context, non-verbal communication, social relationships, and interests). As dependent variables, the group, ASD vs ADHD, was introduced. In the case of the narrative competence, the independent variables introduced in the discriminant analysis were the direct scores on the narrative test (grammatical errors, mean length of utterance, syntactic complexity, semantic errors, perseverations, number of C-units, irrelevant details, cohesive adequacy errors, misattributions, pedantic language, and inferential comprehension), introducing the group (ASD vs ADHD) as dependent variable.

\subsection{Comparison of children with TD, ASD, and ADHD on communicative competence, assessed with the CCC-2}

The MANCOVA performed to evaluate the main effect of group on the different variables of the CCC-2, controlling for gender, vocabulary, and parents' educational level, was statistically significant [Wilk's Lambda $(\Lambda)=.17, F(20,218)=14.93, p<.001, \eta 2 p=.57$ ]. The statistics for the covariates were gender [Wilk's Lambda $(\Lambda)=.83, F(10,109)=2.12, p=.028, \eta 2 p=.16$ ], vocabulary [Wilk's Lambda $(\Lambda)=.85, F(10,109)=1.88, p=.05, \eta 2 p=.15]$, and parents' educational level [Wilk's Lambda $(\Lambda)=.91, F(10,109)=1.03, p=.42, \eta 2 p=.08$ ]

The confirmation ANCOVAs yielded the following results (see table 2); significant differences were found on speech, $F 1,118=13.72 p<.004, \eta 2 p=.19$; syntax, F1,118=8.37p<.004, $\eta 2 p=$ .12 ; semantics, $F 1,118=25.85 p<.004, \eta 2 p=.30$; coherence, $F 1,118=37.03 p<.004, \eta 2 p=$ .38 ; inappropriate initiation $\mathrm{F} 1,118=54.60 \mathrm{p}<.004, \mathrm{\eta} 2 \mathrm{p}=.48$; stereotyped language, $\mathrm{F} 1,118=$ 
$71.79 p<.004, \eta 2 p=.54$; use of context, $\mathrm{F} 1,118=106.24 p<.004, \eta 2 p=.64$; non-verbal communication, $\mathrm{F} 1,118=68.11 \mathrm{p}<.004, \mathrm{\eta} 2 \mathrm{p}=.53$; social relationships, $\mathrm{F} 1,118=53.52 \mathrm{p}<$ $.004, \mathrm{\eta} 2 \mathrm{p}=.47 ;$ and interests, $\mathrm{F} 1,118=64.83 \mathrm{p}<.004, \mathrm{\eta} 2 \mathrm{p}=.52$. Likewise, significant differences were found on pragmatic composite, $\mathrm{F} 1,118=112.42 \mathrm{p}<.004, \mathrm{\eta} 2 \mathrm{p}=.65$; and on the general communication composite, $\mathrm{F} 1,118=93.42 \mathrm{p}<.004, \eta 2 \mathrm{p}=.61$.Post hoc analyses revealed significant differences between the TD group and the clinical groups on all the CCC-2 variables analyzed in this study. In addition, on stereotyped language, use of context, nonverbal communication, interests, and the indices of pragmatic communication and general communication, significant differences were observed between the two clinical groups, as table 2 shows.

In the CCC-2, the ANOVAS without including the covariates maintained the significant differences between the groups in all the variables analyzed (TD, ASD, ADHD). However, the value of the effect size was higher in this case.

-Insert Table 2-

\subsection{Comparison of children with TD, ASD and ADHD on the narrative task}

The MANCOVA performed to evaluate the main effect of group on the different variables on the narrative tasks, controlling for gender, vocabulary, and parents' educational level, was statistically significant [Wilk's Lambda $(\Lambda)=.67, \mathrm{~F}_{(22,216)}=2.14, p=.003, \eta^{2} p=.18$ ]. The confirmation ANCOVAs (see table 3) showed significant differences in irrelevant details, $F_{1,118}=$ $6.04 p<.005, \eta^{2} p=.09$; misattributions, $F_{1,118}=9.98 p<.005, \eta^{2} p=.14$; and inferential comprehension, $F_{1,118}=7.26 p<.005, \eta^{2} p=.11$. Regarding the narrative task, the ANOVAS without including the covariates showed that the cohesive adequacy errors variable also reached significance levels $\left(F_{1,121}=3.86 p=.024, \eta^{2} p=.06\right)$.

Post hoc analyses revealed significant differences between the TD group and the clinical groups on the inferential comprehension variable, and between the TD group and the ASD 
group on the irrelevant details variable. Moreover, on misattributions, significant differences were observed between the two clinical groups.

-Insert Table 3-

\subsection{Discriminant capacity of the communicative competences of children with ASD and children with ADHD using the CCC-2}

The discriminant function that included the different communicative competences revealed a significant association between the groups and the variables of non-verbal communication, stereotyped language, use of context, and interests [Wilk's Lambda $(\Lambda)=.26 ; \mathrm{X}^{2}=108.48, \mathrm{gl}=$ $6, p<.001]$. The analysis of the structural matrix that lists the pooled within-groups correlations between discriminating variables and the standardized canonical discriminant function showed a greater discriminant power of the use of context (discriminant load $=.757$ ) than of interests (discriminant load $=.427$ ), non-verbal communication (discriminant load $=.418$ ), and stereotyped language (discriminant load $=.346$ ). The functions of the centroids in the groups indicated a mean tendency toward negative scores in the ASD group (-1.34), compared to a positive tendency in the ADHD group (2.00). In all, $97.7 \%$ of the cases were correctly classified according to the crossed-validation method. The function showed greater classification power in the case of the ASD group (100\%), compared to the ADHD group (94.3\%) (See figure 1).

-Insert Figure 1-

\subsection{Discriminant capacity of the communicative competences of children with ASD and children with ADHD using the narrative test}

The discriminant function revealed a significant association between the groups and number of units, irrelevant details, and misattributions [Wilk's Lambda $(\Lambda)=.91 ; \mathrm{X}^{2}=7.02, \mathrm{gl}=1, p=.005$ ]. 
A more detailed analysis of the structural matrix showed a greater discriminant power of misattributions than the other two variables. The functions of the centroids in the groups indicated a mean tendency toward positive scores in the ASD group (.25), compared to a negative tendency in the ADHD group (-.37). In all, $64.4 \%$ of the cases were correctly classified according to the crossed-validation method, with the function showing greater classification power in the ASD group (75\%) than in the ADHD group (48.6\%) (see figure 2).

\section{-Insert Figure 2-}

Finally, when both instruments, the CCC-2 and the narrative task, were put together a single analysis, we achieved greater predictive power. Specifically, $96.6 \%$ of the cases were correctly classified according to the crossed-validation method, with the function showing greater classification power in the ASD group (100\%) than in the ADHD group (91.4\%)

\section{Discussion}

The first objective of this study was to assess the profile of alterations presented by children with ADHD and children with ASD in their linguistic and communicative abilities, evaluated, on the one hand, by the parent ratings on the CCC-2 questionnaire and, on the other, through the narration of a story.

Regarding parent ratings on the CCC-2, the results obtained on the different subscales on the general communication composite (GCC) and on the non-standardized pragmatic composite (PC) revealed that the group with ASD and the group with ADHD had communication difficulties that significantly differed from the TD group. However, these deficits were not as severe in the group with ADHD as in the group with ASD. These results are consistent with those reported by Kuijper et al. (2017) and partially replicate the findings by Geurts and Embrechts (2008) and Helland et al. (2012), who also found a significantly higher linguistic performance of the group with TD, whereas general communicative score GCC was not able to differentiate between ADHD and ASD groups.

In addition, the children with ADHD and with ASD did not present significant differences in structural linguistic aspects, specifically, on the scales of speech and semantics. No differences 
were found either on aspects related to coherence or on inappropriate initiation. By contrast, the group with ASD obtained significantly inferior results to those of the ADHD group on the scales of stereotyped language, non-verbal communication and use of context. Therefore, these pragmatic indicators, rather than the structural ones, differentiate the linguistic and communicative profiles of the two groups. The characteristics of stereotyped language and difficulty in the use of gestures are part of the description of ASD included in the DSM-5 (APA, 2013). Likewise, in the comparative study by Grzadzinski et al. (2016), stereotyped utterances on the ADI-R were the repetitive symptoms most clearly associated with ASD. In the same study, non-verbal communication, assessed with the ADOS, was able to significantly differentiate the group with ASD from the group with ADHD. Finally, the observed discrepancies in the use of context, more affected in ASD, could support the idea of "contextual blindness" proposed by Vermeulen (2015) who, in his neurocognitive characterization of ASD, raises a difficulty in taking the context into account when trying to make sense of what is perceived. Moreover, and based on the behavioral phenotype of ASD, the restriction in interests was another variable that made it possible to significantly discriminate children with ASD and children with $A D H D$, an aspect that, along with stereotyped language, can be related to the scant flexibility described in autism (Landa, 2000).

One noteworthy result, coinciding with other studies (Helland et al., 2012; Bishop \& Baird, 2001), was that, according to the parents' estimations, the social relationships of the children with ASD and with ADHD were affected similarly. Although the impairment in social interaction is a core aspect of the characterization of ASD, it is also true that people with ADHD experience equally severe social difficulties (Cervantes, Matson, Adams, Williams, Goldin, \& Jang, 2013). It should also be mentioned that the majority of the participants in the ADHD group in our study showed the combined presentation, which has been associated with greater social and behavioral alterations (Mikami, Huang-Pollock, Pfiffner, \& McBurnett, 2007). Given the relevance of social adjustment in personal, academic, and job functioning, further studies would have to clarify the factors intervening in each case.

With regard to the analysis of the narrative ability, neither the productivity indicators nor the syntactic or semantic indicators were able to differentiate the performance of the three groups considered. A striking finding is the contrast between these indicators and on the CCC-2 scales 
that assess these aspects: whereas the CCC-2 detected worse performance in the clinical groups than in the TD group, the narration did not lead to this significant differentiation. It is likely that the narrative used in this study does not 'stretch' children sufficiently, and that the children with TD tend to use simpler language than they are capable of (Bishop \& McDonald, 2009). In fact, research has shown that the nature of story task can make a difference in the quality of the narratives that children tell (Gazella \& Stockman, 2003; Schneider \& Dubé, 2005). In any case, the mean scores on the structural variables in the narration (grammatical errors or syntactic complexity, for example) indicate a lower performance of the clinical groups, with high inter-individual variability.

Contrary to the structural indicators, again the pragmatic variables selected to assess the narration made it possible to determine relative differences between groups, mainly in the adequate interpretations of scenes and events unfold in the story. On the one hand, both the group with ADHD and the group with ASD obtained worse performance than the TD group, specifically on including irrelevant details. On the other hand, the group with ASD differed from the group with $A D H D$ due to the greater number of erroneous interpretations made (misattributions). Furthermore, inferential comprehension of the story was assessed, especially inferences about the reasons for the characters' mental states or considering the context in the interpretation of the events. Both the group with ASD and the group with ADHD obtained significantly lower scores than the TD group, which seems to indicate a lack of comprehension of social situations and mental states. Studies point out that ToM difficulties are present in both disorders, although the performance of individuals with ADHD seems to lie midway between ASD and healthy controls (Miranda, Berenguer, Roselló, Baixauli, \& Colomer, 2017) and might improve with age (Bora \& Pantelis, 2016). Likewise, the literature has shown difficulties in inferential comprehension processes in both ASD (Dennis, Lazenby, \& Lockyer, 2001) and ADHD (Berthiaume, Lorch, \& Milich, 2010). Future comparative studies should perform a detailed analysis of different types of inferences and possible mechanisms influencing their elaboration.

In summary, in the communication field, stereotyped language, the use of gestures and the interpretation of context seem to be specific difficulties of children with ASD when compared to children with ADHD. However, both disorders share difficulties in pragmatic variables such as 
coherence and inappropriate initiations in daily interactions. Similarities are also observed concerning pragmatic indicators such as cohesive adequacy, the inclusion of irrelevant details and perseverations in narrative discourse. It is possible that these communicative characteristics that share both disorders respond to different neuropsychological explanations. For example, for individuals with ADHD, the lack of coherence related to the inclusion of irrelevant details could be explained by executive functioning deficits, in particular, planning/organization, working memory or impulsivity, as has been shown in other studies (Ygual, Roselló, \& Miranda, 2010). In contrast, and without underestimating the deficits in executive funcioning (Ozonoff, Pennington, \& Rogers, 1991), the Weak Coherence Account (Happé \& Frith, 2006), that is, a processing style characterized by preferential attention to details at the expense of integrating globality, could explain the irrelevant information included by children with ASD, as shown by Barnes and Baron-Cohen (2012). There is data that support the idea that pragmatic difficulties in ADHD are not primary, but the result of an inability to manage with efficiency all the necessary information that is updated in the communicative act (Rints, McAuley, \& Nilsen, 2014). On the contrary, deficits in pragmatic consciousness would be nuclear in individuals with ASD (Rodríguez Muñoz, 2012). Obviously, these interpretations are merely speculative since the mechanisms underlying de pragmatic impairments in ASD and ADHD are complex and cannot be ascertained from the results of this study. Intensive comparative work is needed that demonstrates the scope of the diverse explanatory theories.

The second objective of this study set out to identify the subscales of the CCC-2 and the indicators of narrative ability that have the greatest capacity to precisely classify the participants in the diagnostic groups studied. These variables were, in the CCC-2, non-verbal communication, stereotyped language, restriction of interests, and use of context, aspects that are more affected in ASD than in ADHD. In the narrative task, misattributions appear to be the strongest indicator to differentiate the groups. Along general lines, the results coincide with those contributed by Grzadzinski et al (2016) using other assessment instruments, such as the ADOS and the ADI-R.

In quantitative terms, the CCC-2 includes a larger number of discriminative between-groups variables. Bishop and McDonald (2009) also found that parent report indexes from the CCC-2 did better than a narrative task in distinguishing groups of language impairment in children. 
Obviously, the narrative task used does not involve the complexity of social interactions in daily life, where it is necessary to flexibly combine different kinds of information in a changing environment, in order to adapt to the different demands of situations and conversation partners. In any case, the two assessment procedures can be considered complementary and we cannot dispense with the information provided by the narrative, given its connections with academic skills such as reading comprehension or written expression. Even more, when joining in an analysis the CCC-2 and the narrative task, they had greater predictive power.

Finally, a series of limitations of our study should be mentioned. On the one hand, the type of task -a fictitious story with visual support - restricts the possibility of generalization to other types of narration assessment methods. On the other hand, the narrations were only audiorecorded and it was not possible to make an analysis of non-verbal communication. In addition, in the sample of participants, boys are overrepresented, so that it is important to be cautious when generalizing the results to the characterization of the communicative profile of girls. Apart from these considerations, the in-depth analysis of specific similitudes and differences in the communicative competence of children with ASD and with ADHD has direct clinical implications for optimizing the assessment process and for planning the treatment. The information gathered from the CCC-2 and a narrative sample can be carefully analyzed in order to design interventions that best fit the profile of difficulties and strengths in the use of language, and employ the treatment strategies best suited to the pragmatic alterations observed.

Certainly, more studies are needed with broader samples to analyze the communicative profile of neurodevelopmental disorders, using other instruments and the ratings of other significant informants in the life of the child (therapists, teachers). Further research is warranted on the analysis of samples of language in interactions with peers in order to capture the use of language in everyday contexts and foster the ecological validity of the results. It is also important to address objectives not analyzed in previous studies (Kuijper et al, 2017). For example, it is essential to explore the relationship with other aspects of executive functioningplanning or flexibility, for example- as well as social cognition, combining neuropsychological tests with information about the child's daily life in the school and home environments. 
In conclusion, a complete assessment and a correct identification of deficits and capacities play a key role to adequately address the communicative impairments that children with ASD and ADHD experience. These impairments are constant in different languages and cultures, which provides solidity to the general communicative characterization of both disorders. This work, at least partially, points to key aspects in order to know better these two neurodevelopmental conditions and to profile the intervention targets that may enhance children's development.

\section{Acknowledgements}

This work is supported by the Spanish project PSI2016-78109 (AEI/FEDER, UE) and the predoctoral fellowship UV-INV-PREDOC15-265889

\section{Conflicts of interest}

The authors declare that there is no conflict of interest

\section{References}

Adams, C. (2002). Practitioner Review: the assessment of language pragmatics. Journal of Child Psychology and Psychiatry, 43(8), 973-987.

American Psychiatric Association (2013). Diagnostic and statistical manual of mental disorders. Washington, DC: American Psychiatric Association.

Baixauli, I., Colomer, C., Roselló, B., \& Miranda, A. (2016). Narratives of children with highfunctioning autism spectrum disorder: A meta-analysis. Research in Developmental Disabilities, $59,234-254$

Banney, R.M., Harper-Hill, K. \& Arnott, W.L. (2015). Observation Schedule and narrative assessment: evidence for specific narrative impairments in autism spectrum disorders. International Journal of Speech Language Pathology, 17(2), 159-171.

Barnes, J.L., \& Baron-Cohen, S. (2012). The big picture: storytelling ability in adults with autism spectrum disorders. Journal of Autism and Developmental Disorders 42(8), 1557-1565. 
Baron-Cohen, S., Leslie, A.M., \& Frith, U. (1985). Does the autistic child have a theory of mind? Cognition, 21(1), 37-46.

Bellani, M., Moretti, A., Perlini, C., \& Brambilla, P. (2011). Language disturbances in ADHD. Epidemiology and Psychiatric Sciences, 20(4), 311-315.

Berthiaume, K., Lorch, E., \& Milich, R. (2010). Getting clued in: inferential processing and comprehension monitoring in boys with ADHD. Journal of Attention Disorders, 14(1), 31-42.

Bishop, D.V.M. (1998). Development of the Children's Communication Checklist: a method for assessing qualitative aspects of communicative impairment in children. Journal of Child Psychology and Psychiatry, 39(6), 879-891.

Bishop, D.V.M. (2003). The Children's Communication Checklist Second Edition (CCC-2). London: The Psychological Corporation.

Bishop, D.V.M., \& Baird, G. (2001). Parent and Teacher report of pragmatic aspects of communication: Use of the Children's Communication Checklist in a clinical setting. Developmental Medicine and Child Neurology, 43(12), 809-818.

Bishop, D.V.M., \& McDonald, D. (2009). Identifying language impairment in children: combining language test scores with parental report. International Journal of Language and Communication Disorders, 44(5), 600-615.

Bora, E., \& Pantelis, C. (2016). Meta-analysis of social cognition in attention-deficit/hyperactivity disorder (ADHD): comparison with healthy controls and autistic spectrum disorder. Psychological Medicine, 46(4), 699-716.

Botting, N. (2002). Narrative as a tool for the assessment of linguistic and pragmatic impairments. Child Language Teaching and Therapy 18(1), 1-21.

Cervantes, P.E., Matson, J.L., Adams, H.L., Williams, L.W., Goldin, R.L., \& Jang, J. (2013). Comparing social skill profiles of children with autism spectrum disorders versus children with attention deficit hyperactivity disorder: Where the deficits lie. Research in Autism Spectrum Disorders, 7(9), 1104-1110.

Crespo-Eguílaz, N., Magallón, S., Sánchez-Carpintero, R., \& Narbona J. (2016). La adaptación al castellano de la Children's Communication Checklist permite detectar las dificultades en el 
uso pragmático del lenguaje y diferenciar subtipos clínicos. Revista de Neurología, 62 (Supl 1), S49-57.

Dennis, M., Lazenby, A.L., \& Lockyer, L. (2001). Inferential language in high-function children with autism. Journal of Autism and Developmental Disorders, 31(1), 47-54.

Gazella, J., \& Stockman, I.J. (2003). Children's story retelling under different modality and task conditions: implications for standardizing language sampling procedures. American Journal of Speech-Language Pathology, 12(1), 61-72.

Geurts, H.M., \& Embrechts, M.T. (2008). Language profiles in ASF, SLI, and ADHD. Journal of Autism and Developmental Disorders, 38(10), 1931-1943.

Geurts, H.M., Verte, S., Oosterlaan, J., Roeyers, H., Hartman, C.A., Mulder, E.J., BerckelaerOnnes, I.A., \& Sergeant, J.A. (2004). Can the Children's Communication Checklist differentiate between children with autism, children with ADHD, and normal controls? Journal of Child Psychology and Psychiatry, 45(8), 1437-1453.

Griffin, T.M., Hemphill, L., Camp, L., \& Wolf, D.P. (2004). Oral discourse in the preschool years and later literacy skills. First Language, 24(2), 123-147.

Grzadzinski, R., Dick, C., Lord, C., \& Bishop, S. (2016). Parent-reported and clinician-observed autism spectrum disorder (ASD) symptoms in children with attention deficit/hyperactivity disorder (ADHD): implications for practice under DSM-5. Molecular Autism, 7(7), 1-12. Happé, F., \& Frith, U. (2006). The weak coherence account: detail-focused cognitive style in autism spectrum disorders. Journal of Autism and Developmental Disorders, 36(1), 5-25.

Helland, W.A., Biringer, E., Helland, T., \& Heimann, M. (2012) Exploring language profiles for children with ADHD and children with Asperger Syndrome. Journal of Attention Disorders, 16(1), $34-43$

Helland, W.A., Helland, T., \& Heimann, M. (2014). Language profiles and mental health problems in children with specific language impairment and children with ADHD. Journal of Attention Disorders, 18(3), 226-235.

Kaufman, A.S., \& Kaufman, N.I. (2000). K-BIT. Test Breve de Inteligencia de Kauffman. Madrid: Pearson. 
Kinnear, P.R., \& Gray, C.D. (2000). SPSS for windows made simple. East Sussex: Psychology Press.

Kuijper, S.J.M., Hartman, C.A., Bogaerds-Hazenberg, S.T.M., \& Hendriks, P. (2017). Narrative production in children with Autism Spectrum Disorder (ASD) and children with AttentionDeficit/Hyperactivity Disorder (ADHD): Similarities and Differences. Journal of Abnormal Psychology, 126(1), 63-75.

Landa, R. (2000). Social Language Use. In: A.Klin, F. Volkmar, \& S.Sparrow (Eds.) Asperger Syndrome (pp.125-155). New York: The Guilford Press.

Leonard, L. (2009). Cross-linguistic studies of child language disorders. In R.G Schwartz, (ed). Handbook of Child Language Disorders (pp. 308-324). New York, Psychology Press.

Liles, B. (1985). Cohesion in the narratives of normal and language-disordered children. Journal of Speech and Hearing Research 28(1), 123-133.

Loban, W. (1976). Language development: Kindergarten through grade twelve. Urbana: National Council of Teachers of English.

Lord, C., Rutter, M., DiLavore, P.C., \& Risi, S. (2000). Autism Diagnostic Observation Schedule (ADOS). Los Angeles: Western Psychological Services.

Mayer, M. (1974). Frog goes to dinner. New York: Dial Books.

Mikami, A., Huang-Pollock, C., Pfiffner, L., \& McBurnett, K. (2007). Social skills differences among attention-deficit/hyperactivity disorder types in a chat room assessment task. Journal of Abnormal Child Psychology, 35(4), 509-521.

Miller, J., \& Chapman, R. (2000). Systematic analysis of language transcripts. Computer software. Language Analysis Laboratory, Madison: University of Wisconsin.

Miranda, A., Berenguer, C., Roselló, B., Baixauli, I., \& Colomer, C. (2017). Social cognition in children with high-functioning autism spectrum disorder and attention-deficit/hyperactivity disorder. Associations with executive functions. Frontiers in Psychology, 8, 1035.

Miranda, A., Baixauli, I., Colomer, C., y Roselló, B. (2013). Autismo y trastorno por déficit de atención/hiperactividad: convergencias y divergencias en el funcionamiento ejecutivo y la teoría de la mente. Revista de Neurología, 57, S177-S184. 
Norbury, C.F., Gemmell, T., \& Paul, R. (2014). Pragmatics abilities in narrative production: a cross-disorder comparison. Journal of Child Language, 41(3): 485-510.

Norbury, C.F., Nash, M., Bairds, G., \& Bishop, D.V.M. (2004). Using a parental checklist to identify diagnostic groups in children with communication impairment: A validation of the Children's Communication Checklist-2. International Journal of Language and Communication Disorders, 39(3), 345-364.

Ozonoff, S., Pennington, B. F., \& Rogers, S. J. (1991). Executive function deficits in highfunctioning autistic individuals: Relationship to theory of mind. Journal of Child Psychology and Psychiatry, 32(7), 1081-1105.

Rints, A., McAuley, T., \& Nilsen, E. (2015). Social communication is predicted by inhibitory ability and ADHD traits in preschool-aged children: a mediation model. Journal of Attention Disorders, 19(10), 901-911.

Rodríguez Muñoz, F. (2012). La conciencia pragmática de adultos con síndrome de Asperger. Revista de Logopedia, Foniatría y Audiología, 32, 21-31.

Rumpf, A-L., Kamp-Becker, I., Becker, K., \& Kauschke, C. (2012). Narrative competence and internal state language of children with Asperger syndrome and ADHD. Research in Developmental Disabilities, 33(5), 1395-1407.

Rutter, M., Bailey, A., \& Lord, C. (2003). SCQ. The Social Communication Questionnaire. Torrance, CA: Western Psychological Services.

Rutter, M., Le Couteur, A., \& Lord, C. (2006). ADI-R; Entrevista Clínica para el Diagnóstico del Autismo-Revisada. Madrid: TEA Ediciones.

Schneider, P., \& Dubé, R.V. (2005). Story presentation effects on children's retell content. American Journal of Speech-Language Pathology, 14(1), 52-60.

Schuch, J.M., Eigsti, I.M., \& Mirman, D. (2016). Discourse comprehension in autism spectrum disorder: effects of working memory load and common ground. Autism Research, 9(12), 13401352. 
Siller, M., Swanson, M.R., Serlin, G., \& George, A. (2014). Internal state language in the storybook narratives of children with and without autism spectrum disorder: Investigating relations to theory of mind abilities. Research in Autism Spectrum Disorders, 8(5), 589-596.

Strong, C. (1998). The Strong Narrative Assessment Procedure. Eau Claire: Thinking Publications.

Vermeulen, P. (2015). Context blindness in Autism Spectrum Disorder: not using the forest to see the trees as trees. Focus on Autism and Other Developmental Disabilities, 30(3), 182-192. Ygual, A., Roselló, B., \& Miranda, A. (2010). Funciones ejecutivas, comprensión de historias y coherencia narrativa en niños con trastorno por deficit de atención con hiperactividad. Revista de Logopedia, Foniatría y Audiología, 30(3), 151-161.

Wechsler, D. (2003). Wechsler Intelligence Scale for Children. Fourth Edition (WISC-IV). San Antonio. TX: The Psychological Corporation.

Wiesner, D. (1998). Tuesday. New York: Clarion Books. 